\title{
Association of obesity, diabetes and linked complications with gut microbiota
}

\author{
Amina Arif ${ }^{1 *}$, Zobaria Khan ${ }^{1}$, Seemab Khalid ${ }^{1}$, Muhammad Azam \\ Gujjar $^{1}$, Rafique Ahmed ${ }^{2}$ and Mushtaq Ahmad Saleem ${ }^{1}$ \\ 1. Faculty of Life Sciences, University of Central Punjab, Lahore-Pakistan \\ 2. Govt. Kot Khawaja Saeed Teaching Hospital, Lahore-Pakistan \\ *Corresponding author's email: draminaarif@gmail.com \\ Citation \\ Amina Arif, Zobaria Khan, Seemab Khalid, Muhammad Azam Gujjar, Rafique Ahmed and Mushtaq Ahmad \\ Saleem. Association of obesity, diabetes and linked complications with gut microbiota. Pure and Applied Biology. \\ Vol. 7, Issue 4, 1326-1338. http://dx.doi.org/10.19045/bspab.2018.700154
}

\begin{tabular}{llll}
\hline \hline Received: 26/05/2018 & Revised: 20/08/2018 & Accepted: 29/08/2018 & Online First: 08/09/2018 \\
\hline
\end{tabular}

\section{Abstract}

Gut microbiota is the microorganism community comprising of bacteria, eukaryotes and archaea as well as different viruses that live in the small intestinal tract and gut. Human have clusters of bacteria in the intestine. Gut microbiota encompasses tens of trillions microorganisms, including different types of bacteria with more than 3 million genes. In normal humans, microbiota usually weighs up to $2 \mathrm{~kg}$. In simple words, microbiota in our intestine is like a person's identity card. Microbiota may corresponds to many inter-related diseases such as obesity, diabetes and complications linked to them e.g. renal toxicity, kidney stones, diabetes retinopathy, hypertension, atherosclerosis, diabetic foot ulcer, Alzheimer's disease and cystic fibrosis. Germ free animals protected against obesity when transferred with gut microbes from conventionally raised animals resulted in dramatic increase in their body fat content and resistance to insulin. Moreover, composition of the gut microbiota has shown to differ in lean and obese humans changed rapidly in response to dietary factors. There are some factors that affect the composition of gut microbiota such as food, disease state, medications, genetics of host etc. This review highlights the fact that modification of gut microbiota may be a beneficial way in the treatment of obesity, diabetes and other metabolic disorders.

Keywords: Alzheimer's disease; Cystic fibrosis; Diabetes mellitus; Gut microbiota; Obesity

\section{Introduction}

Disorders like obesity have extended to dangerous level worldwide. During last few decades' over-weight and its related problems like type 2 diabetes (T2D) has increased to exponential level [1]. Inactive life style and extra food utilization has been considered as main reason for this obesity scourge [2]. Term gut microbiota covers all micro-organisms living in gastrointestinal (GI) tract. Most of gut microbiota that exist in large intestine play an important role in the vitamin synthesis, digestion and metabolism. Although the correct mechanism is far from being well recognized, it is accepted that gut microbes can upsurge energy creation from food, they also can donate to regulate fatty acids tissue composition and low grade inflammation [3]. These activities besides other have initiated linkage between gut microbiota and over-weight. Genetic factors and some environmental factors induce changes in gut microbiota leading to the metabolic diseases [4]. Although the accurate 
contribution of gut microbiota is not very clear in the development of diabetes and obesity because of so many reasons including complicated changes in gut microbes' composition, inherited changes and large differences between individuals of the population in study [5]. In spite of regulations made by gut microbes having massive therapeutic prospective, they can also help to recover the growing obesity and related complications mostly when combined with exercise and diet [6].

All over the world, the major health problem is diabetes, according to an estimation $9 \%$ of the population is suffering from this disease. This can affect standard of life and often has led to major issues including risk of kidney failure, heart attack and overall mortality. Due to the inheritance based complicated changes in gut microbes' composition and large differences between individuals of population in the study, the human body pool anchorages trillions of bacteria that were genetic contents of our micro flora and 150 times extra in number as other body parts [7]. There are three domains of gut microbiota including (Bacteria, Eukaryote and Archaea) along with their viruses, that dominated anaerobic bacteria. Each individual harbors 160 species and has been given new idea that cored gut microbiota at functional level and necessary for gut functioning in the ecosystem [8]. Almost 90\% of prevalent bacterial species are grouped into two phyla Bacteroidetes (Gram negative) and Firmicutes (Gram positive) [9]. The gut microbiota helps in maturing and regulating the immune system and also protects from pathogens. They regulate the intestinal hormone secretion for gastrointestinal movement, they synthesize vitamin $\mathrm{K}$ and $\mathrm{B}$ vitamin (Folate, Vitamin B12) and they create short-chain fatty acids (SCFAs) by fermentation of carbohydrates which are nondigestible, conventionally bacteria are being studied by culture methods. Yet it's not easy to culture bacterial strain so the cultureindependent method has been established [10]. Culture-independent methods are easier because they take more advantages and approach of next-generation sequencing expertise to know DNA microbes from fecal trials; they are generally well-thought-out illustrative of distal gut microbiota.

Complicated relationship between diabetes, over-weight and gut microbiota was uncovered with emerging evidences. Obesity and its related problems have reached to a disturbing stage globally. During the last few years' exponential rise in the number of people suffering from fatness and its related syndromes such as T2D has been experienced [11]. All of us have our own unique microbiota and gut microbiota (microorganism genes). Microbiota genes are hundredfold higher than the numbers of genes of human [12]. A study investigated that the effects of nutrients (such as fats, roughage) and dietary habits (weather vegetarians or omnivores) in diverse population have permitted that the classification of human population will be based on their microfilm's genetic abundance [13]. Gut microbiota is classified into enterotype, dietary components of metabolism and capacity to metabolize drugs depending on their function in different individuals [14]. The existence of microbes that increase metabolism, have drug response to infection, puffiness, resist against cancer and autoimmunity are characters of healthy gut microbiota. The increasing clues tell that gut microbiota are strongly linked to diabetes development [15]. Pathogenic cascade instruct the development of autoimmune pancreatic cells of Langerhans that leads to myenteric neuropathy. Lymphokines are produced in this pathogenic cascade [16]. Through interaction with epithelial cells and enteric nerves system gut microbiota affect the intestinal mucosa that leads to changes in motility, pain, perception and sensory 
function of the gut [17]. Emphasizing the importance of gut microbiota in diabetes to improve the production of novel healing target, for the precaution, cure and reduction in other metabolic disorders of diabetes are some aims that provide mechanistic insights. Change in genes may cause diseases (Alzheimer's, obesity, diabetes, poor physical activity, fetal programming) which are major risk factors of T2DM [18]. Another conformation of microbial community in our gut linked with T2DM is that these microorganisms slow down the distal gut they carry out some important key functions that human hosts are not capable to do by their own.

DNA based microbial study is done through two approaches: targeted 16S rRNA gene sequence and untargeted whole genome shotgun sequencing. This amplification relies on the subsequent sequencing of phylogenetical markers that are used to described those terms in which bacteria are present, their relative profusion and phylogenetic relationship [19]. Microbial genome study, may be partial by primer choice and PCR-related analysis, doesn't provide evidence about bacterial genes and metagenomics sequencing. Whole genome shot-gun sequencing bypasses the preferences and limitations consuming nextgeneration sequencing of microbial DNA without intensification and gives highresolution of bacterial arrangement of gut micro biome, functional capabilities based on metagenomics sequence of European population [11].

\section{Diabetes and gut microbiota}

In diabetic humans there is shortage of consistency in gut microbiota profile. Study of human metagenome-wide association revealed important correlation with certain gut microbes, metabolic pathways and some bacterial genes in diabetic type 2 victims [20, 21]. These victims exhibit high stages of Lactobacillus sp. as related to non-diabetic
Clostridium $s p$. It correlates negatively with fasting glucose, $\mathrm{HbA} 1_{\mathrm{C}}$ and insulin while Lactobacillus sp. Positively correlates with fasting glucose and glycolated hemoglobin $\left(\mathrm{HbA1} 1_{\mathrm{C}}\right)$ levels. Plasma triglycerides or Cpeptides are positively linked with adiponectin and high-density lipoprotein (HDL) cholesterol [22]. Furthermore, onset based metagenomics clusters in obese and genetically diet-induced leptin-resistant mice, 26 distinctive bunches were found when associated normal mice with diabetic [23]. Microbiota has low amount of Roseburia intestinalis and Faecalibacterium prausnitzii (both butyrate producing bacteria) and high level of Lactobacillus gasseri, Streptococcus mutants as well as clostridiales members in different population levels. Administration of metformin caused and increased Akkermansia muciniphila, gram negative bacteria in mucous layer [24]. A. muciniphila concentration associates inversely with the presence of diabetes and loss of weight. Induced improvement in weight loss, tolerance of glucose, and inflammation $[25,26]$. Management of a prebiotics such as oligofructose increases $A$. muciniphila level, with some beneficial effects on metabolic mechanism, neomycin given to non-obese diabetic (NOD) mice increases the concentration of $A$. muciniphila and increases glucose homeostasis. Some of the Firmicutes and Clostridium sp. were seriously reduced in the patients where diabetes was tried to control [27]. In same way relationship between Bacteroidetes to Firmicutes and Bacteroides/Prevotella groups to $C$. coccoides/Eubacterium rectal group are related positively with plasma glucose. Likewise, Betaproteobacteria class was highly increased in diabetic vs. nondiabetic people showing mutual relationship with plasma glucose [28]. There might be inflammation-trigging effect due to auto immune diabetes on the intestinal microbiota [29]. 
Gut-Microbiota and Complications linked to type 2 Diabetes

Composition of gut microbiota changes with the diseased status, T2D is one of them. There are many related complications which cause the changing in the microbes' quality as well as quantity.

\section{Renal toxicity \& kidney stones}

Renal toxicity is a poisonous effect of some substances, both chemical \& medical ways. Stones in kidney result from clinical conditions of acute kidney toxins for example. This is perhaps colonic epithelial permeability resulted due to disruption in the pathological process of chronic kidney toxicity and T2DM. By phylogenetic microarray breakdown, the chronic kidney malady victims exhibit rare variations in 190 microbial functioning taxonomic units (OTUs), precisely the plenty of the Enterobacteriaceae compared to the fit control group [30]. Bioconversion of melamine is done by microbiota of gut. Especially Klebsiella pneumonia is critical in kidney stones formation in renal toxicity [31]. For the improvement of clinical condition of kidney stones patients, some microbes are important like Oxalobacter formigenes [32]. Some frequently used probiotics contain

Lactobacillus and Bifidobacterium which are not able to reduce oxalate kidney stones [33]. Aside from, the level of stone formation due to calcium oxalate perhaps depends on the microbiota. This confirmation was found by low assertion of vitamin $\mathrm{K}$ epoxide reductase level complex subunit 1 (VKORC1) in patients with calcium oxalate urolithiasis (formation of stones in bladder). VKORC1 working should be affected through gut bacteria by creating vitamin K2 [34].

\section{The diabetic retinopathy}

The diabetic retinopathy occurs in above $60 \%$ of T2DM patients [35]. As predicted, high proportion of coagulase negative
Staphylococci \& higher gram positive bacteria frequency was noticed in those diabetic patients that mostly have retinopathy [36]. Predominant organisms found in T2DM patients were Staphylococcus aureus. $S$. aureus were isolated from the T1DM patient's eyes who had higher occurrence frequency than that of healthy person [37]. Parkinson's disease is a term degenerative of central system that maintains the motor system affects. Difficulty with walking, rigidity and chronic diabetic neuropathy are the major complications with Parkinson's disease in T2DM [38, 39].

\section{Hypertension}

T2DM and blood pressure are clinically related with each other. Cardiovascular disease is also a risk factor and metabolic syndrome. The current evidences suggest that this syndrome is comparatively regulated by gut microbiota [40]. Yet the case of hypertension is very little to be recognized it is also the characteristic of host gut microbiota. Gut microbiota regulates the blood pressure. One experimental finding using mouse model supports the hypothesis that the response of propionate, appears on renal olfactory receptor 78(Olfr78) [41]. In kidney and blood vessels the short-chain fatty acid (SCFA) receptor is expressed as well as blood pressure regulation has been reported. Gut microbes derive these fatty acids, in specific proportion through both receptors in regulation process of blood pressure. It has been also reported that Lactobacillus johnsonii cannot hardly maintain low blood glucose level but also prevent rats from overhead (BP) by sinking the renal sympathetic nerve movement and parasympathetic nerve activity that can be boosted up through the sympathoadrenal axis [42].

\section{Atherosclerosis}

Most of the type 2 diabetic victims have a higher level of serum lipids that leads them to atherosclerosis. Associative connections in 
diabetes and atherosclerosis have been found through atherosclerotic plaque in the mouth and gut of atherosclerotic patients [43]. Plenty of linkages between Veillonella and Streptococcus in the oral fissure of plaque have also been reported. Numerous oral and intestinal bacterial taxa are associated with the plasma cholesterol levels. Bile salt hydrolase activity of probiotics protects the cells from the toxicity of conjugated bile salts [44]. Moreover there are some reports that symbiotic brew containing Lactobacillus acidophilus, Bifidobacterium bifidum and oligofructose, clearly increase plasma (high density lipoprotein) cholesterol and reduce the ailment of impaired fasting glycaemia in aged patients of T2DM [45].

\section{Diabetic foot ulcers}

Limb loss and diabetic foot ulcer both are interconnected to an increase the chance of age related diabetes or T2DM. Many wellsearched microorganism Staphylococcus specie and $P$. aeruginose had been detected from diabetic foot ulcers patients [46].

Staphylococcus species being coagulasenegative are the main planter of foot normal flora; these are identified as a strong participants for the infection related to $S$. aureus. During last few years, it has been examined that there is an increase in the percentage of conversion of non-pathogenic staphylococcus to pathogen $S$. aurues. Although present in the small concentration on the feet of diabetic men as contrast to standard the small concentration is present on men of diabetic feet [47]. After the analysis of the microbes in foot ulcers of diabetic patient it was found that depth of ulcer and period of the microbial growth are negatively related with profusion of Staphylococcus whereas the time duration of the ulcers was positively related to the bacterial protein and all this work was done by pyro-sequencing of 16S rRNA gene of bacteria [48].

\section{Alzheimer's disease (AD)}

The risk of Alzheimer's disease (AD) can also be increased by diabetes type 2 and have a common pathogenic mechanism [49]. The potential mechanism that link two medical conditions, include insulin resistance or role of insulin deficiency that facilitates cerebel $\beta$ amyloidogenesis, which increases the danger of dementia in diabetic patients [50]. Diabetes type 3 could be considered as Alzheimer's disease [51]. A very minute data exists to understand the residential flora of Alzheimer's disease patients but how they are related to each other is badly perceived. There is a study that openly relates to the gut physiology and structure of microbiota in which alteration in gut was categorized by an increase of gram-negative bacteria that was escorted by mucosal disturbance in AD transgenic mice [52]. The testing area of gut microbiota in AD is under studies, might be in future there will be a possibility to treat AD through enteric bacteria considerable. Usually putative drugs like indole propionic acids (IPAs) are used to treat AD and type 2 diabetes [53]. The plasma amino acid by products include bioactive indole comprising metabolites moreover conversion of indole 3 propionic acid was known reliant on gut microflora by colonization with the bacterium Clostridium sporogenes [54]. Thus extraction of microbiota seems to be an essential way to overhaul the plasma IPA level. Metabolic characteristics of the AD was the disappearance of GABA (A) receptors in the hippocampus of the brain [55]. There are some direct evidences that show interaction between host metabolisms of residence flora, which deals with new potential or treatment goals for AD.

\section{Cystic fibrosis}

Cystic fibrosis (CF) patients are also linked with T2DM [56]. Microbiota in CF respiratory tract also have an imperative position in its pathogenesis; evidences show that most common bacteria that are collected from airways of cystic fibrosis victims were 
Pseudomonas aeruginosa, Haemophilus influenza, S. aureus, Burkholderia cepacia complex species [57]. From highthroughput sequencing method, like 16S rRNA amplicon pyro-sequencing was done to figure out the genetic bases of the airway microbiota. But through a direct sampling of explanted lungs only one or three species were found dominated in CF lungs [58]. Micro flora in the throat and sputum could not resemble to the normal micro flora that had been observed previously.

\section{Factors affecting on gut microbiota composition}

Numerous factors like food, level of disease condition, medication moreover host genetics, effect the configuration of gut microbiota (Figure 1). The constitutions of gut microbiota are persistently changed and influence the health and welfare of host especially in the disease condition as well as during treatment through diverse medicine like antibiotics.

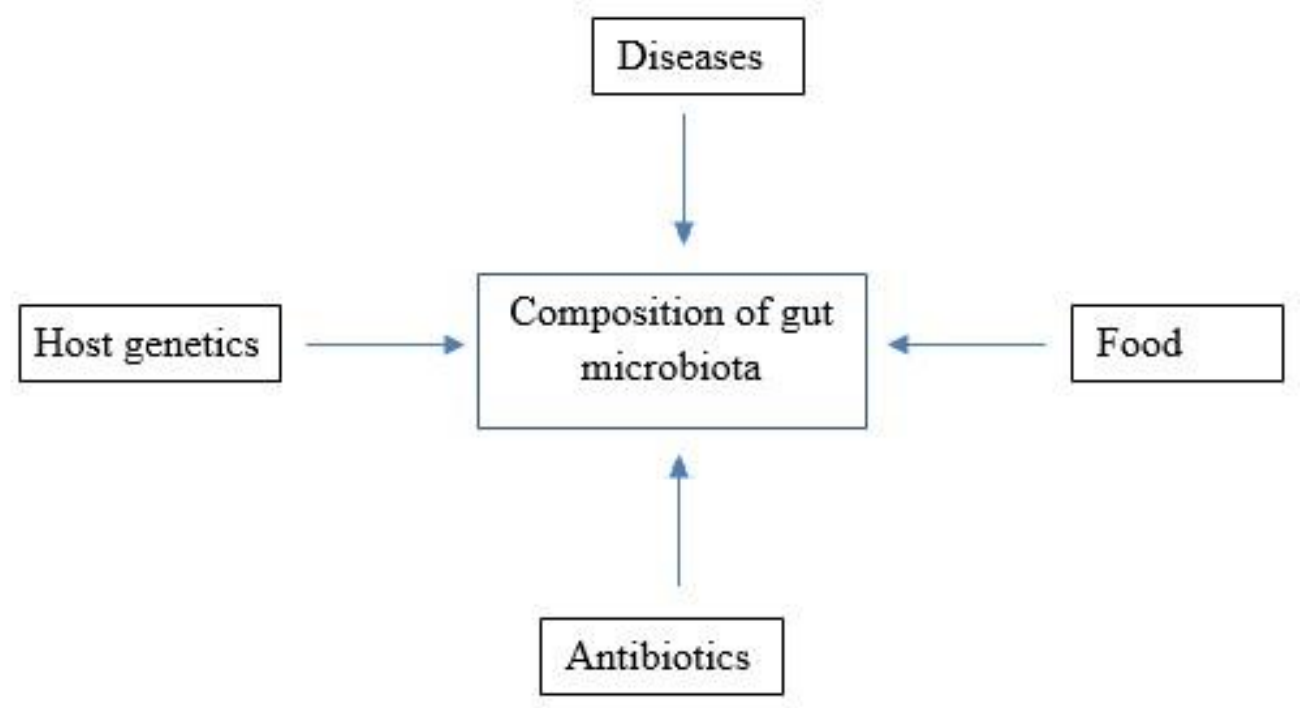

Figure 1. Some aspects that effect the gut microbiota configuration. Gut microbiota constitution depends on the food, diseased state, medication and host genetics

Relationship between antibiotics and increase in weight is also well recorded. The usage of intra Venus injection of vancomycin plus gentamycin has been derived with remarkable weight gain [59]. There is the relation between antibiotics exposure and their affects during 6 months of age to increase in body weight in healthy youngsters [60]. Use of antibiotics results, drop in bacterial diverseness, stereotypic declines as well as augmentation of specific taxa [61]. Recovery of normal microbiota can be long dependent on the type of antibiotic and the range of certain antibiotic treatment [62].
Clindamycin have longer effects persevering up to 4 years and being a broad spectrum antibiotic [63]. Moreover, the treatment with antibiotics facilitates the relocation of antibiotic resistance gene and virulent specie that leads to the increasing drug resistance and this stress is due to disruption of normal flora [64]. It's foremost to perceive the role of antibiotics that modify microbiota and their involvement to weight increase, possibly weight drops as well as other illness. It has been suggested that genetic differences in host can only accounts $12 \%$ but diet can 
account for $57 \%$ of the variations [65]. The main contributor of gut diversity is diet.

The most dietary strategies are prebiotics and probiotics that are established to regulate the configurational activity of gut microbiota. Nonpathogenic microorganism e.g. prebiotic, are used as food ingredient for the benefits of the host health. The existence of bile salt hydrolase $(\mathrm{BSH})$ in probiotics makes them more permissive to bile salts, which is also helpful in reducing the blood cholesterol level of the host [66]. Starch and insulin are prebiotic compounds that are used by food industry to change the configuration of gut microbiota to value human health, these compounds mostly target Lactobacillus and Bifidobacterium [67].

Recent research tells that prebiotics and probiotics (symbiotic) can also thicken human body making it fat and large [68]. The humanized mice produce by incorporating the human genes, cells, tissues or organs could be used to examine the reaction of diet on microbiota, exchanging mice from low fat, rich diet called western diet, high fat sugar diet that changed the anatomy of microbiota within one day $[69,70]$. Mice fed with western diet up surged the number of Erysipelotrichia bacteria, a class in the Firmicutes phylum and lowered the Bacteroids spp. compared to the mice that were given vegetarian diet rich in nutritional fibers, later had low Bacteroids spp. as compared to control E.coli and other bacteria. Table 1 explains the change in gut microbiota on the ingestion of different types of diet that have different level of sugar, fat, starch, protein, vegetarian or calorie limited food and western diet.

Table 1. Effects of different type of foods on the diversity of gut microbiota

\begin{tabular}{|l|l|}
\hline Food type & Effects on bacteria \\
\hline \multirow{5}{*}{ Vegetarian } & Decreased Acteriods spp. E. coli, Bifidobacterium spp. and \\
& $\begin{array}{l}\text { Enterobacteriaceae spp. [70] } \\
\text { Less Enterobacteriaceae and more Bactericides spp. [71] } \\
\text { Increase Bacteroidetes } \text { and decrease Firmicutes and Enterobacteriaceae. } \\
\text { [72] }\end{array}$ \\
\hline \multirow{5}{*}{ High fat } & Decrease genera in class Clostridia in the ileum. \\
& Escalation of Bacteriodetes in large intestine. [73] \\
& Increase Lactobacillus spp., Bifidobacterium spp., Bactericides spp. and \\
& Enterococcus spp. \\
& Decrease Clostridium leptum and Enterobacter spp. [74] \\
& Increase Firmicutes to Bacteriodetes ratio, and increased \\
& Enterobacteriaceae spp. [75]
\end{tabular}

\section{Linkage of obesity with gut microbes}

Metabolic defects roll out all the universe like overweight and obesity. The presence of T2D is the result of overweight and obesity. Environmental factors like behavior and interaction between environment and genetics are basic contributors of T2D frequency and obesity. Among surrounding determinants, gut microbiota of human are decisive mediators of diabetes pathogenicity and obesity [71]. Microbiota plays an active role in glucose and lipid breakdown and holds defensive function in metabolic regulation [72]. Due to lack of microbiota functional diversity and composition intrinsic and extrinsic factors initially disturb the gut microbes. The result of this disturbance is shifted from normobiosis to dysbiosis.

Obesity is associated with dysbiosis, a condition that is described by the 
modification in gut microbiota make up, alteration in bacterial metabolic action, in other words it puts modifications in the domesticated distribution of the bacterial fraternity. Variations in the constitution of gut microbiota could enhance the energy removal and intestinal monosaccharide's absorption from undigested food constituents (generally carbohydrates through short-chain fatty acids fabrication and De Novo hepatic lipogenesis) [73]. In addition, dysbiosis can boost up fatty acid loading in adipocytes, restrict the fasting-induced adipose factor in gut, which, sequentially increases enzyme action of lipoprotein lipase [74]. Dietinduced fatness in germ-free mice could reserve the cellular energy-dependent protein kinase concentration; this is the main expected mechanism putting balance in gut microbiota composition. Due to the unusual composition of incurable low-grade inflammation, the host provides easy and effective systemic exposure to lipopolysaccharides (LPS) [75]. Energy storage and $\mathrm{G}$ protein-coupled receptor activation accompanied by an emergence with SCFA signaling molecules [76, 77]. Nowadays dysbiosis in intestine is critical for relation of interaction of gut microbiota and appropriate fat storage. The enhancement of obesity-related problems is metabolic endotoxaemia [78]. Glycolipid molecule, that are resultant from external membrane of Gram-positive bacteria, induce potential to the innate immune-system, account for the adiposity, insulin resistance (IR) and production of triglycerides endotoxaemia. [79]. Comparatively high number of Bacteriodetes and reduced amount of Firmicutes was observed in mice nursed on high-fat diet (HFDS), which reduced weight on little calorie diet [77]. Bifidobacterium species replace variation in microbiota, minimize the overabundance of Formicates and LPS-producing proteobacteria, helps in improving systemic inflammation by fabrication of B cells and cytokinesis (IL-6, MCP-1, TNF- $\alpha$, IL-17) [78].

Triglycerides, insulin, low level of cholesterol and lowering the body weight help in increasing restoration of insulin sensitivity and oral glucose forbearance, all these factors are involved in improving the metabolic dysfunctions [80]. In diabetic/obese persons, rapid diabetic cancellation and metabolic enhancement along with the weight loss can be achieved by a bariatric surgery-named as, Roux-en-Y Gastric Bypass (RYGB). E.coli and other microbes' population increase after three months that inversely correlates with leptin level and fat mass as a result of several changes in food intake. Three months later, decrease in lactic acid bacteria (LAB), Lactobacillus, Pediococcus group, Bifidobacterium and Leuconostoc coordinate to help in improvement of insulin sensitivity and oral glucose tolerance. These conclusions indicate that the reduction in weight and overall variations in inflammatory eminence can be improved by bionetwork of gut microbiota [81].

\section{Conclusion}

The accumulative evidences sturdily suggest that the gut microbiota play an important role in the regulation of metabolism and weight maintenance in humans as well as put impact on the development and progression of obesity plus other metabolic disorders, including type 2 diabetes. Constitution of the gut microbiota has been shown to diverge in lean and obese humans and change quickly in response to dietary factors. There are some factors that affect the composition of gut microbiota such as food, disease state, medications, genetics of host etc. Manipulation of the gut microbiome represents a novel approach in treating obesity, diabetes and complications linked to them such as renal toxicity, kidney stones, diabetes retinopathy, hypertension, atherosclerosis, diabetic foot ulcer, Alzheimer's disease and cystic fibroses. 


\section{Authors' contributions}

Conceived and designed the experiments: A Arif \& R Ahmed, Performed the experiments: Z khan \& S Khalid, Analyzed the data: MA Gujjar, Contributed materials/ analysis/ tools: MA Saleem, Wrote the paper: A Arif \& $\mathrm{Z}$ khan.

\section{Acknowledgement}

Authors acknowledge University of Central Punjab for providing all the facilities required to write this review.

\section{References}

1. $\mathrm{Ng} \mathrm{M}$, Fleming $\mathrm{T}$, Robinson $\mathrm{M}$, Thomson B, Graetz N, Margono C, Mullany EC, Biryukov S, Abbafati C, Abera SF \& Abraham JP (2014). Global, regional, and national prevalence of overweight and obesity in children and adults during 1980-2013: a systematic analysis for the Global Burden of Disease Study 2013. The lancet 384: 766-781.

2. Jebb SA \& Moore MS (1999). Contribution of a sedentary lifestyle and inactivity to the etiology of overweight and obesity: current evidence and research issues. Med Sci Sport Exer 31: S534-541.

3. Murphy EF, Cotter PD, Healy S, Marques TM, O'sullivan O, Fouhy F, Clarke SF, O'toole PW, Quigley EM, Stanton C \& Ross PR (2010). Composition and energy harvesting capacity of the gut microbiota: relationship to diet, obesity and time in mouse models. Gut, gut-2010.215665.

4. Kallus SJ \& Brandt LJ (2012). The intestinal microbiota and obesity. J Clin gastroenterol 46: 16-24.

5. Brown K, DeCoffe D, Molcan E \& Gibson DL (2012). Diet-induced dysbiosis of the intestinal microbiota and the effects on immunity and disease. Nutrients 4: 10951119.

6. Razmpoosh E, Javadi M, Ejtahed HS \& Mirmiran P (2016). Probiotics as beneficial agents in the management of diabetes mellitus: a systematic review. Diabetes/Metab Res Rev 32: 143-168.

7. Gareau MG, Sherman PM \& Walker WA (2010). Probiotics and the gut microbiota in intestinal health and disease. Nat Rev Gastroenterol and Hepatol 7:503.

8. Qin J, Li R, Raes J, Arumugam M, Burgdorf KS, Manichanh C, Nielsen T, Pons N, Levenez F, Yamada T \& Mende DR (2010). A human gut microbial gene catalogue established by metagenomic sequencing. Nature 464 (7285): 59.

9. Tremaroli V \& Bäckhed F (2012) Functional interactions between the gut microbiota and host metabolism. Nature 489, 242.

10. Bishehsari F, Engen PA, Preite NZ, Tuncil YE, Naqib AM. Shaikh M, Rossi S, Wilber SJ, Green BR, Hamaker K, Khazaie RM, Voigt CB, Forsyth \& Keshavarzian A (2018). Dietary Fiber Treatment Corrects the Composition of Gut Microbiota, Promotes SCFA Production, and Suppresses Colon Carcinogenesis. Genes. 9.

11. Ferrante D, Linetzky B, Ponce M, Goldberg L, Konfino J \& Laspiur S (2014). Prevalence of overweight, obesity, physical activity and tobacco use in Argentine youth: Global school-based student health survey and global youth tobacco survey, 2007-2012. Arch Argent Pediatr 112: 496-503.

12. Qin J, Li R, Raes J, Arumugam M, Burgdorf KS, Manichanh C, Nielsen T, Pons N, Levenez F, Yamada T \& Mende DR (2010). A human gut microbial gene catalogue established by metagenomic sequencing. Nature 464: 59.

13. Conlon MA \& Bird AR (2014). The impact of diet and lifestyle on gut microbiota and human health. Nutrients 7 : $17-44$.

14. Wu GD, Chen J, Hoffmann C, Bittinger K, Chen YY, Keilbaugh SA, Bewtra M, Knights D, Walters WA, Knight $\mathrm{R}$ \& Sinha R (2011). Linking long-term dietary patterns with gut microbial enterotypes. Science 334: 105-108.

15. Haro C, Montes-Borrego M, RangelZúñiga OA, Alcalá-Díaz JF, GómezDelgado F, Pérez-Martínez P, DelgadoLista J, Quintana-Navarro GM, Tinahones 
FJ, Landa BB \& López-Miranda J (2015). Two healthy diets modulate gut microbial community improving insulin sensitivity in a human obese population. Metabolis 10: 11 .

16. Burokas A, Moloney RD, Dinan TG \& Cryan JF (2015). Microbiota regulation of the mammalian gut-brain axis. Adv Appl Microbiol 91: 1-62.

17. Chen J, Li Y, Tian Y, Huang C, Li D, Zhong Q \& Ma X (2015). Interaction between microbes and host intestinal health: modulation by dietary nutrients and gut-brain-endocrine-immune axis. Curr Protein Pept Sci 16(7): 592-603.

18. Grarup N, Sandholt CH, Hansen $\mathrm{T} \&$ Pedersen O (2014). Genetic susceptibility to type 2 diabetes and obesity: from genome-wide association studies to rare variants and beyond. Diabetologia 57: $1528-1541$

19. Kuczynski J, Lauber CL, Walters WA, Parfrey LW, Clemente JC, Gevers D \& Knight R (2012). Experimental and analytical tools for studying the human microbiome. Nat Rev Genet 13: 47.

20. Larsen N, Vogensen FK, van den Berg FW, Nielsen DS, Andreasen AS, Pedersen BK, Al-Soud WA, Sørensen SJ, Hansen LH \& Jakobsen M (2010). Gut microbiota in human adults with type 2 diabetes differs from non-diabetic adults. PloS One e9085.

21. Lê KA, Li Y, Xu X, Liu T, Yang W, He F, Su K, Cai DH, Go VL, Pandol S \& Hui H (2013). Alterations in fecal Lactobacillus and Bifidobacterium species in type 2 diabetic patients in Southern China population. Front Physiol 3: 496.

22. Derrien M, Vaughan EE, Plugge CM \& de Vos WM (2004). Akkermansiamuciniphila gen. nov., sp. nov., a human intestinal mucin-degrading bacterium. Int J Syst Evol Microbiol 54: 1469-1476.

23. Everard A, Lazarevic V, Derrien M, Girard M, Muccioli GG, Neyrinck AM, Possemiers S, Van Holle A, François P, de Vos WM \& Delzenne NM (2011).
Responses of gut microbiota and glucose and lipid metabolism to prebiotics in genetic obese and diet-induced leptinresistant mice. Diabetes 60: 2775-2786.

24. Karlsson CL, Önnerfält J, Xu J, Molin G, Ahrné S \& Thorngren-Jerneck K (2012). The microbiota of the gut in preschool children with normal and excessive body weight. Obesity 20: 2257.

25. Shin NR, Lee JC, Lee HY, Kim MS, Whon TW, Lee MS \& Bae JW (2013). An increase in the Akkermansia spp. population induced by metformin treatment improves glucose homeostasis in diet-induced obese mice. Gut gutjnl2012-303839.

26. Hansen $\mathrm{CH}$, Krych L, Nielsen DS, Vogensen FK, Hansen LH, Sørensen SJ, Buschard K \& Hansen AK (2012). Early life treatment with vancomycin propagates Akkermansia muciniphila and reduces diabetes incidence in the NOD mouse. Diabetologia 55: 2285-2294.

27. Lau K, Benitez P, Ardissone A, Wilson TD, Collins EL, Lorca G, Li N, Sankar D, Wasserfall C, Neu J \& Atkinson MA (2011). Inhibition of type 1 diabetes correlated to a Lactobacillus johnsonii N6. 2-mediated Th17 bias. J Immunol 186: 3538-3546.

28. Hänninen A, Nurmela R, Maksimow M, Heino J, Jalkanen S \& Kurts C (2007). Islet $\beta$-cell-specific $\mathrm{T}$ cells can use different homing mechanisms to infiltrate and destroy pancreatic islets. Am J Pathol 170(1): 240-250.

29. Wen L, Ley RE, Volchkov PY, Stranges PB, Avanesyan L, Stonebraker AC, Hu C, Wong FS, Szot GL, Bluestone JA \& Gordon JI (2008). Innate immunity and intestinal microbiota in the development of Type 1 diabetes. Nature 455(7216): 1109.

30. Vaziri ND, Wong J, Pahl M, Piceno YM, Yuan J, DeSantis TZ, Ni Z, Nguyen TH \& Andersen GL (2013). Chronic kidney disease alters intestinal microbial flora. Kidney Int 83(2): 308-315. 
31. Zheng X, Zhao A, Xie G, Chi Y, Zhao L, Li H, Wang C, Bao Y, Jia W, Luther M, $\mathrm{Su} M$ (2013). Melamine-induced renal toxicity is mediated by the gut microbiota. Sci Transl Med 5(172): 172ra22-172ra22.

32. Duncan SH, Richardson AJ, Kaul P, Holmes RP, Allison MJ \& Stewart CS (2002). Oxalobacter formigenes and its potential role in human health. Appl Environ Microbiol 68(8): 3841-3847.

33. Turroni S, Vitali B, Bendazzoli C, Candela M, Gotti R, Federici F, Pirovano F \& Brigidi P (2007). Oxalate consumption by Lactobacilli: evaluation of oxalyl-CoA decarboxylase and formyl-CoA transferase activity in Lactobacillus acidophilus. J Appl Microbiol 103(5): 1600-1609.

34. Oldenburg J, Marinova M, Müller-Reible C \& Watzka M (2008). The vitamin K cycle. Vitam Horm 78: 35-62.

35. Fong DS, Aiello L, Gardner TW, King GL, Blankenship G, Cavallerano JD, Ferris FL 3RD \& Klein R (2004). Gardner retinopathy in diabetes. Diabetes care 27: 84-87

36. Karimsab D \& Razak S (2013). Study of aerobic bacterial conjunctival flora in patients with diabetes mellitus. Nep J Oph 5: 28-32.

37. Bilen H, Ates O, Astam N, Uslu H, Akcay G \& Baykal O (2007). Conjunctival flora in patients with type 1 or type 2 diabetes mellitus. Adv Ther 24: 1028-1035.

38. Cereda E, Barichella M, Pedrolli C, Klersy C, Cassani E, Caccialanza R \&Pezzoli G (2011). Diabetes and risk of Parkinson's disease: a systematic review and metaanalysis. Diabetes care 34(12): 26142623.

39. Kusbeci T, Kusbeci ÖY, Aktepe OC, Yavas G \&Ermis SS (2009). Conjunctival flora in patients with Parkinson's disease. Curr Eye Res 34: 251-256.

40. Tilg H \& Kaser A (2011). Gut microbiome, obesity, and metabolic dysfunction. J Clin Invest 21: 2126-2132.
41. Pluznick JL, Protzko RJ, Gevorgyan H, Peterlin Z, Sipos A, Han J, Brunet I, Wan LX, Rey F, Wang T \& Firestein SJ (2013). Olfactory receptor responding to gut microbiota-derived signals plays a role in renin secretion and blood pressure regulation. Proc Natl Acad Sci U S A 110: 4410-4415.

42. Tanida M, Yamano T, Maeda K, Okumura N, Fukushima Y \& Nagai K (2005). Effects of intraduodenal injection of Lactobacillus johnsonii La1 on renal sympathetic nerve activity and blood pressure in urethane-anesthetized rats. Neurosci Lett 389: 109-114.

43. Koren O, Spor A, Felin J, Fåk F, Stombaugh J, Tremaroli V, Behre CJ, Knight R, Fagerberg B, Ley RE \& Bäckhed F (2011). Human oral, gut, and plaque microbiota in patients with atherosclerosis. Proc Natl Acad Sci U S A 108: 4592-4598.

44. Ooi LG \& Liong MT (2010). Cholesterollowering effects of probiotics and prebiotics: a review of in vivo and in vitro findings. Int J Mol Sci 11: 2499-2522.

45. Moroti C, Magri LFS, de Rezende Costa M, Cavallini DC \& Sivieri K (2012). Effect of the consumption of a new symbiotic shake on glycemia and cholesterol levels in elderly people with type 2 diabetes mellitus. Lipids Health Dis 11: 29 .

46. Grice EA \& Segre JA (2011). The skin microbiome. Nat Rev Microbiol 9: 244.

47. Redel H, Gao Z, Li H, Alekseyenko AV, Zhou Y, Perez-Perez GI, Weinstock G, Sodergren E \& Blaser MJ (2013). Quantitation and composition of cutaneous microbiota in diabetic and nondiabetic men. J Infect Dis 207: 11051114

48. Gardner SE, Hillis SL, Heilmann K, Segre JA \& Grice EA (2013). The neuropathic diabetic foot ulcer microbiome is associated with clinical factors. Diabetes 62: 923-930.

49. Vagelatos NT \& Eslick GD (2013). Type 2 diabetes as a risk factor for Alzheimer's 
disease: the confounders, interactions, and neuropathology associated with this relationship. Epidemiol Rev 35: 152-160.

50. Gardner SE, Hillis SL, Heilmann K, Segre JA \& Grice EA (2013). Alzheimer's disease and diabetes: new insights and unifying therapies. Curr diabetes rev 9: 218-227.

51. de la Monte S M \& Wands JR (2008). Alzheimer's disease is type 3 diabetesevidence reviewed. J Diabetes Sci Technol 2: 1101-1113.

52. Karri S, Martinez VA \& Coimbatore $G$ (2010). Effect of dihydrotestosterone on gastrointestinal tract of male Alzheimer's disease transgenic mice. Indian J Exp Biol 48 (05): 453-465.

53. Kuhn B, Hilpert H, Benz J, Binggeli A, Grether U, Humm R, Märki HP, Meyer M $\&$ Mohr P (2006). Structure-based design of indole propionic acids as novel PPAR $\alpha / \gamma$ co-agonists. Bioorg \& Med Chem Lett 16: 4016-4020.

54. Wikoff WR, Anfora AT, Liu J, Schultz PG, Lesley SA, Peters EC \& Siuzdak G (2009). Metabolomics analysis reveals large effects of gut microflora on mammalian blood metabolites. Proc Natl Acad Sci U S A 106: 3698-3703.

55. Limon A, Reyes-Ruiz JM \& Miledi R (2012). Loss of functional GABAA receptors in the Alzheimer diseased brain. Proc Natl Acad Sci U S A 109 (25): 1007110076.

56. Milla CE, Billings J \& Moran A (2005). Diabetes is associated with dramatically decreased survival in female but not male subjects with cystic fibrosis. Diabetes Care 28: 2141-2144.

57. Harrison F (2007). Microbial ecology of the cystic fibrosis lung. Microbiology 153: 917-923.

58. Goddard AF, Staudinger BJ, Dowd SE, Joshi-Datar A, Wolcott RD, Aitken ML, Fligner CL \& Singh PK (2012). Direct sampling of cystic fibrosis lungs indicates that DNA-based analyses of upper-airway specimens can misrepresent lung microbiota. Proc Natl Acad Sci U S A 109: 13769-13774.

59. Thuny F, Richet H, Casalta JP, Angelakis E, Habib G \& Raoult D (2010). Vancomycin treatment of infective endocarditis is linked with recently acquired obesity. PLoS One 5(2): e9074.

60. Saari A, Virta LJ, Sankilampi U, Dunkel L, \& Saxen H (2015). Antibiotic exposure in infancy and risk of being overweight in the first 24 months of life. Pediatrics 135: 617-626.

61. Keeney KM, Yurist-Doutsch S, Arrieta MC \& Finlay BB (2014). Effects of antibiotics on human microbiota and subsequent disease. Annu Rev Microbiol 68: 217-235.

62. Panda S, Casellas F, Vivancos JL, Cors MG, Santiago A, Cuenca S, Guarner F \& Manichanh C (2014). Short-term effect of antibiotics on human gut microbiota. PloS One 9(4), e95476.

63. Jakobsson HE, Jernberg C, Andersson AF, Sjölund-Karlsson M, Jansson JK \& Engstrand L (2010). Short-term antibiotic treatment has differing long-term impacts on the human throat and gut microbiome. PloS One 5(3): e9836.

64. Modi SR, Collins JJ \& Relman DA (2014). Antibiotics and the gut microbiota. J Clin Invest 124: 4212-4218.

65. Brown K, DeCoffe D, Molcan E \& Gibson DL (2012). Diet-induced dysbiosis of the intestinal microbiota and the effects on immunity and disease. Nutrients 4(8): 1095-1119.

66. Jones M, Martoni C \& Prakash S (2012). Cholesterol lowering and inhibition of sterol absorption by Lactobacillus reuteri NCIMB 30242: a randomized controlled trial. Eur J Clin Nutr 66:1234.

67. Macfarlane GT, Steed H \& Macfarlane S (2008). Bacterial metabolism and healthrelated effects of galacto-oligosaccharides and other prebiotics. $J$ appl microbiol 104(2): 305-344.

68. De los Reyes-Gavilan CG, Delzenne NM, González ST, Gueimonde M \& Salazar 
Garzo N (2014). Development of functional foods to fight against obesity: Opportunities for probiotics and prebiotics. Agro Food Ind Hi Tech 25: 35.

69. Turnbaugh PJ, Ridaura VK, Faith JJ, Rey FE, Knight R \& Gordon JI (2009). The effect of diet on the human gut microbiome: a metagenomic analysis in humanized gnotobiotic mice. Sci Transl Med 1(6): 6ra14-16ra14.

70. Zimmer J, Lange B, Frick JS, Sauer H, Zimmermann K, Schwiertz A, Rusch K, Klosterhalfen S \& Enck P (2012). A vegan or vegetarian diet substantially alters the human colonic faecal microbiota. Eur $J$ Clin Nutr 66: 53.

71. Larsen N, Vogensen FK, van den Berg FW, Nielsen DS, Andreasen AS, Pedersen BK, Al-Soud WA, Sørensen SJ, Hansen LH \& Jakobsen M (2010). Gut microbiota in human adults with type 2 diabetes differs from non-diabetic adults. PloS One 5(2): e9085.

72. Prakash S, Rodes L, Coussa-Charley M \& Tomaro-Duchesneau C (2011). Gut microbiota: next frontier in understanding human health and development of biotherapeutics. Biologics 5: 71.

73. Schwiertz A, Taras D, Schäfer K, Beijer S, Bos NA, Donus C \& Hardt PD (2010). Microbiota and SCFA in lean and overweight healthy subjects. Obesity 18: 190-195.

74. Bäckhed F, Ding H, Wang, T, Hooper LV, Koh GY, Nagy A, Semenkovich C F, \& Gordon JI (2004). The gut microbiota as an environmental factor that regulates fat storage. Proc Natl Acad Sci USA 101: 15718-15723.

75. Bäckhed F, Manchester JK, Semenkovich CF \& Gordon JI (2007). Mechanisms underlying the resistance to diet-induced obesity in germ-free mice. Proc Natl Acad Sci USA 104: 979-984.

76. Samuel BS, Shaito A, Motoike T, Rey FE, Backhed F, Manchester JK, Hammer RE, Williams SC, Crowley J, Yanagisawa M \&
Gordon JI (2008). Effects of the gut microbiota on host adiposity are modulated by the short-chain fatty-acid binding $\mathrm{G}$ protein-coupled receptor, Gpr41. Proc Natl Acad Sci U S A 105: 16767-16772.

77. Moya-Pérez A, Neef A \& Sanz Y (2015). Bifidobacterium pseudocatenulatum CECT 7765 reduces obesity-associated inflammation by restoring the lymphocyte-macrophage balance and gut microbiota structure in high-fat diet-fed mice. PLoS One 10(7) e0126976.

78. Cani PD, Neyrinck AM, Fava F, Knauf C, Burcelin RG, Tuohy KM, Gibson GR \& Delzenne NM (2007). Selective increases of bifidobacteria in gut microflora improve high-fat-diet-induced diabetes in mice through a mechanism associated with endotoxaemia. Diabetologia 50: 23742383.

79. Walsh CJ, Guinane CM, Hill C, Ross RP, O’Toole PW \& Cotter PD (2015). In silico identification of bacteriocin gene clusters in the gastrointestinal tract, based on the Human Microbiome Project's reference genome database. BMC Microbiol 15: 183.

80. Everard A, Geurts L, Caesar R, Van Hul M, Matamoros S, Duparc T, Denis RG, Cochez P, Pierard F, Castel J \& Bindels LB (2014). Intestinal epithelial MyD88 is a sensor switching host metabolism towards obesity according to nutritional status. Nat Commun 5: 5648.

81. Kong LC, Wuillemin PH, Bastard JP, Sokolovska N, Gougis S, Fellahi S, Darakhshan F, Bonnefont-Rousselot D, Bittar R, Doré J \& Zucker JD (2013). Insulin resistance and inflammation predict kinetic body weight changes in response to dietary weight loss and maintenance in overweight and obese subjects by using a Bayesian network approach. Am J Clin Nutr 98: 1385-1394. 